\title{
Conventional Dissection and Bipolar Electrocauterization Methods of Tonsillectomy: A Comparative Study
}

\author{
Sharma $\mathrm{A}^{1}$, Bhandari $\mathrm{S}^{1}$, Paudel DR ${ }^{1}$
}

\begin{abstract}
Introduction: Tonsillectomy is frequently performed surgical procedure. There are several different methods with varied advantages and disadvantages. In spite of the different techniques available there is no consensus and definite evidence for best method. The most commonly performed are conventional dissection and bipolar electrocauterization methods. Aims: The aim of the study was to compare time required for the completion of surgery, intraoperative and postoperative blood loss along with post operative pain between conventional dissection and bipolar electrocauterization methods. Methods: This comparative study was conducted from August 2019 to March 2021 in total of 30 patients planned for tonsillectomy in department of Otorhinolaryngology, Nepalgunj Medical College Teaching Hospital.In every patient right side tonsillectomy was done with conventional dissection method and left side tonsillectomy was done with bipolar electrocauterization method. Results: The mean age was $27.2 \pm 13.08$ years. The mean duration of surgery was $16.53 \pm 2.43 \mathrm{~min}$ and $11.10 \pm 1.93 \mathrm{~min}$ in conventional dissection method and bipolar electrocauterization method respectively. The difference was statistically significant. Intraoperative blood loss was significantly lower in bipolar electrocauterization method with mean intraoperative blood loss of $19 \pm 4.62 \mathrm{ml}$ in bipolar electrocauterization group and $81.83 \pm 36.54 \mathrm{ml}$ in conventional dissection method. The pain intensity was statistically similar in both methods at all-time intervals post operatively. Conclusion: In tonsillectomy, bipolar electrocauterization method has advantage over conventional dissection method in regards to reduced surgical time and intra operative blood loss, without any significant difference in post-operative pain intensity and post-operative hemorrhage.
\end{abstract}

$\underline{\text { Keywords: Bipolar electrocauterization, Blood loss, Conventional dissection, Post-operative pain, Tonsillectomy }}$

Authors:

1. Dr. Anshu Sharma

2. Dr. Shama Bhandari

3. Prof. Dhundi Raj Paudel

${ }^{1}$ Department of Otorhinolaryngology, Nepalgunj Medical College and Teaching Hospital

\section{Address for Correspondence:}

Dr. Anshu Sharma

Department of Otorhinolaryngology

Nepalgunj Medical College and Teaching Hospital

Nepalgunj, Banke

Phone: 9848031256

E-mail: anshusa.regmi@gmail.com

\section{INTRODUCTION}

Tonsillectomy is one of the oldest and the most common surgical procedure constituting $20 \%$ of all otorhinolaryngology surgeries done worldwide. ${ }^{1,2}$ Although tonsillectomy is a welltolerated surgery, it is still not devoid of complications. ${ }^{3}$ Posttonsillectomy hemorrhage is the most frequently encountered complication after tonsillectomy, in addition to pain, dehydration, airway obstruction, vomiting and pulmonary edema. ${ }^{4}$ The mortality in tonsillectomy has been reported to be 1 per 1100 to 1 per 1600 . Most of these mortalities have been attributed to perioperative bleeding. ${ }^{5}$

Increased post-operative pain intensity indirectly increases chance of secondary hemorrhage as it leads to inadequate oral intake, poor oral hygiene and dehydration which results in infection and early breakage of slough causing disruption of vessels. ${ }^{6}$ Thus proper control of postoperative pain is mandatory not only for the comfort of the patient but also to prevent secondary hemorrhage.

Laser and harmonic scalpel have been seen superior to other technique in term of early recovery, less blood loss and less postoperative pain but their availability, affordability, technicality and maintenance costs is a big issue. ${ }^{7}$ This reason along with the low cost and ease of the procedure conventional dissection and electrocauterization tonsillectomy are still the two most commonly used techniques. ${ }^{8,2}$ Nevertheless there is no consensus in optimal method of tonsillectomy. ${ }^{9}$ Hence we chose to conduct a study comparing conventional dissection and bipolar electrocauterization tonsillectomy.

\section{METHODS}

This single blinded, prospective and comparative study was conducted from August 2019 to March 2021 in Nepalgunj 
Medical College Teaching Hospital, after taking ethical clearance from Institutional Review Committee (IRC). 30 patients of age 13 years and above, who were undergoing tonsillectomy, were enrolled for the study after taking consent. In every patient right side tonsillectomy was done with conventional dissection method and left side tonsillectomy was done with bipolar electrocauterization method. Both methods were carried out in a single patient, so that the individual patient factors were nullified and each patient becomes their own control.

Patients with congenitally malformed tonsils, acute tonsillitis, quinsy, bleeding disorders and patients on antiplatelets and anticoagulants were excluded from the study. In operation table patient were given general anesthesia according to the standard protocol and operated in Rose's position. For better exposure of the surgical field nasal intubation was done.

The operative time was recorded from time of putting the mucosal incision till the achievement of complete hemostasis. Amount of intraoperative blood loss was measured by adding number of cotton balls used for moping and blood present in the suction jar. Fully soaked cotton balls and partially soaked cotton balls were taken as $1 \mathrm{ml}$ and $0.5 \mathrm{ml}$ blood loss respectively.

Post-operative pain was measured at 2, 6, 12, 18, 24 hours and 2 and 10 days respectively, using Numerical Pain Rating Scale as pain measurement tool. ${ }^{10}$

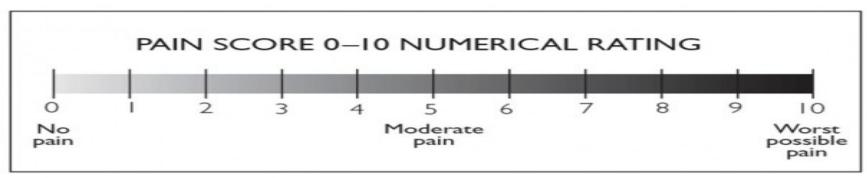

Both primary and secondary hemorrhage if occurred were noted and if required treated. For pain control all the patient received intravenous (IV) paracetamol as a stat dose just after the surgery in recovery room and thereafter when orally allowed they were given tablet (Tab) paracetamol+ ibuprofen thrice a day (TDS) for 5 days according to their body weight. Diclofenac gargle was started as TDS course 12 hours after the surgery for 7 days in all patients.

\section{Statistical Analysis}

Data were analyzed using SPSS 20. Independent t-test was used for analysis. ' $p$ ' valve less than 0.05 was considered significant.

\section{RESULTS}

The mean age of the study population was $27.2 \pm 13.08$ years with the maximum age 68 years and minimum age 13 years. With the numbers of male and female, 14 and 16 respectively, there was no statistically significant difference between them. The mean duration of surgery was $16.53 \pm 2.43 \mathrm{~min}$ and 11.10 $\pm 1.93 \mathrm{~min}$ in conventional dissection method and bipolar electrocauterization method respectively. The difference was statistically significant. Intraoperative blood loss was significantly lower in cauterization method with mean of
$19 \pm 4.62 \mathrm{ml}$ in cauterization method and $81.83 \pm 36.54 \mathrm{ml}$ in conventional dissection method.

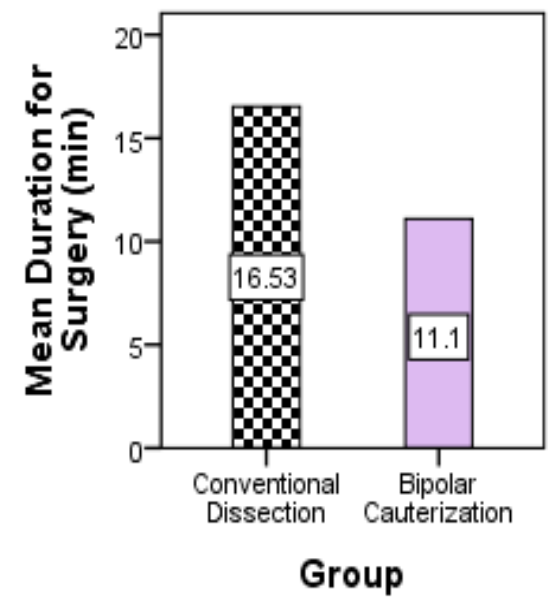

Figure: 1 Comparison of mean duration of surgery

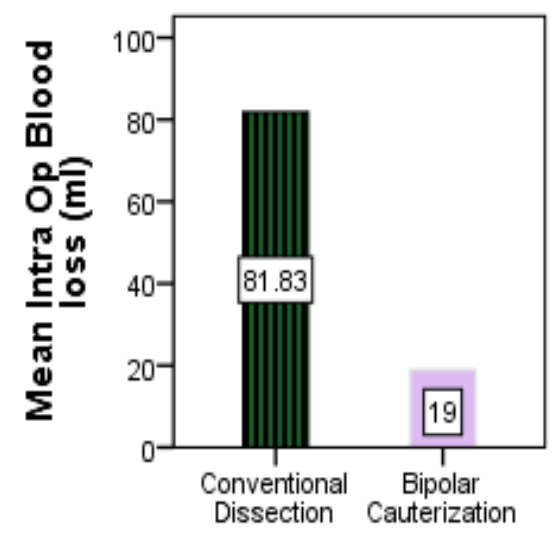

Group

Figure 2: Comparison of mean intra operative blood loss

\begin{tabular}{|c|c|c|c|c|c|}
\hline & Group & $\mathbf{N}$ & Mean & $\begin{array}{c}\text { Std. } \\
\text { Deviation }\end{array}$ & $\begin{array}{c}P \\
\text { Value }\end{array}$ \\
\hline \multirow{2}{*}{$\begin{array}{l}\text { Duration for } \\
\text { Surgery (min) }\end{array}$} & $\begin{array}{l}\text { Conventional } \\
\text { Dissection }\end{array}$ & 30 & 16.53 & 2.432 & \\
\hline & $\begin{array}{c}\text { Bipolar } \\
\text { Cauterization }\end{array}$ & 30 & 11.10 & 1.936 & 0.00 \\
\hline \multirow{2}{*}{$\begin{array}{c}\text { Intra Op Blod } \\
\text { loss (ml) }\end{array}$} & $\begin{array}{l}\text { Conventional } \\
\text { Dissection }\end{array}$ & 30 & 81.83 & 36.542 & \multirow{2}{*}{0.00} \\
\hline & $\begin{array}{c}\text { Bipolar } \\
\text { Cauterization }\end{array}$ & 30 & 19.00 & 4.624 & \\
\hline
\end{tabular}

Table l: Comparison of duration of surgery and intra operative blood loss between the groups 


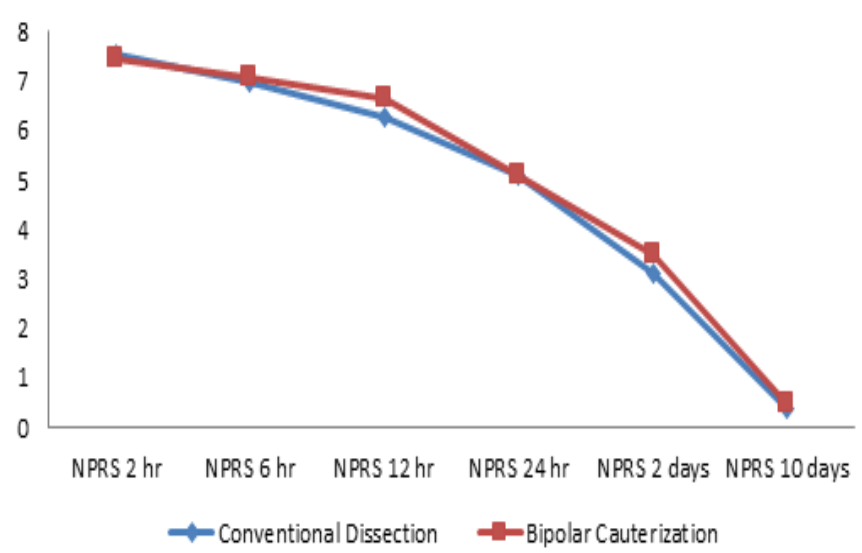

NPRS $=$ Numerical Pain Rating Scale

Figure 3: Comparison of pain intensity in at different time intervals between the groups

\begin{tabular}{|c|c|c|c|c|c|}
\hline $\begin{array}{l}\text { Pain rating } \\
\text { scale } \\
\text { (NPRS) }\end{array}$ & Group & $\mathbf{N}$ & Mean & $\begin{array}{c}\text { Std. } \\
\text { Deviation }\end{array}$ & $\begin{array}{c}P \\
\text { Value }\end{array}$ \\
\hline \multirow[b]{2}{*}{$2 \mathrm{hr}$} & Conventional & 30 & 7.53 & 1.008 & \\
\hline & $\begin{array}{c}\text { Bipolar } \\
\text { cauterization }\end{array}$ & 30 & 7.47 & 1.042 & 0.802 \\
\hline \multirow[b]{2}{*}{$6 \mathrm{hr}$} & Conventional & 30 & 7.00 & 1.017 & \\
\hline & $\begin{array}{c}\text { Bipolar } \\
\text { Cauterization }\end{array}$ & 30 & 7.07 & 0.980 & 0.797 \\
\hline \multirow[b]{2}{*}{$12 \mathrm{hr}$} & Conventional & 30 & 6.27 & 0.980 & \\
\hline & $\begin{array}{c}\text { Bipolar } \\
\text { Cauterization }\end{array}$ & 30 & 6.67 & 1.028 & 0.128 \\
\hline \multirow[b]{2}{*}{$24 \mathrm{hr}$} & Conventional & 30 & 5.10 & 0.960 & \\
\hline & $\begin{array}{c}\text { Bipolar } \\
\text { Cauterization }\end{array}$ & 30 & 5.07 & 1.015 & 0.896 \\
\hline \multirow[b]{2}{*}{2 days } & Conventional & 30 & 3.10 & 1.447 & \\
\hline & $\begin{array}{c}\text { Bipolar } \\
\text { Cauterization }\end{array}$ & 30 & 3.50 & 1.456 & 0.290 \\
\hline \multirow[b]{2}{*}{10 days } & Conventional & 30 & 0.37 & 0.765 & \\
\hline & $\begin{array}{c}\text { Bipolar } \\
\text { Cauterization }\end{array}$ & 30 & 0.47 & 0.860 & 0.636 \\
\hline
\end{tabular}

Table II: Comparison of pain intensity at different point intervals between the groups

The pain intensity was measured with numerical pain rating scale at 2, 6, 12, 24 hours, 2 and 10 days postoperatively. The pain intensity was statistically similar in both methods at alltime intervals post operatively. In our study only one patient had primary hemorrhage from the conventional dissection method side who resolved with packing with tranexamic acid. Whereas with both methods wound site was healthy, no postoperative hemorrhage and no post-operative infection was seen.

\section{DISCUSSION}

The surgical removal of tonsils has been performed as long as three thousand years, as mentioned in Hindu literature.
Cornélio Celsus, in the $1^{\text {st }}$ century B.C, was the first to describe tonsillectomy surgery. ${ }^{11}$ At the beginning of the twentieth century, Worthington (1907) and Waugh (1909) described the technique of tonsillectomy via a dissection method. Goycolea in 1982 described electrodissection by using monoplar diathermy and Pang YT 10 years later reported the first tonsillectomy by bipolar electrocautery. ${ }^{1}$ Although in search for method to decrease the procedure time, blood loss during surgery, postoperative hemorrhage, pain and hasten the wound healing CO2 laser, bipolar radiofrequency and harmonic scalpel are added. ${ }^{12,13}$ They are still not common due to their high cost and technical difficulties. In such situation conventional dissection method and bipolar electrocauterization method tonsillectomy continues to be the most used technique. ${ }^{8}$

Excessive heat of $400^{\circ} \mathrm{C}$ to $600^{\circ} \mathrm{C}$ generated from electrocautery can cut tissue and coagulate vessels quickly resulting in reduced operative time, intraoperative bleeding and primary hemorrhage in comparison to conventional dissection. But the main issue is that the heat generated also injures the surrounding tissue including pillar mucosa, which leads to increase post-operative pain, increase risk of necrosis and infected slough formation and thus secondary hemorrhage..$^{9,14,15,16}$ It is important to minimize pain following tonsillectomy not just for patient comfort but also because it may impair swallowing, with a risk of dehydration, infection and secondary haemorrhage. ${ }^{6}$ Post-tonsillectomy hemorrhage may require further surgical intervention and can be life threatening. ${ }^{6,17}$ In our study the duration for the surgery was $16.53 \pm 2.43 \mathrm{~min}$ and $11.10 \pm 1.93 \mathrm{~min}$ in conventional dissection and bipolar cauterization methods respectively. The time for completion of surgery was significantly less in electrocauterization method. The study done by Singh OP ${ }^{18}$ in 60 patients shows the similar result with mean duration of intraoperative time of $21.75 \mathrm{~min}$ and $11.75 \mathrm{~min}$ in conventional dissection method and bipolar electrocauterization method respectively. Likewise the study done by Al-Shehri in 2020 in 50 patients shows operation time with bipolar cauterization is significantly reduced when compared to conventional method.

The intraoperative blood loss was statistically significantly lower in bipolar method. The mean blood loss was $81.83 \pm 36.54 \mathrm{ml}$ and $19 \pm 4.62 \mathrm{ml}$ in conventional dissection and bipolar electrocauterization method respectively. A study done by Malik $\mathrm{S}^{9}$ showed $75 \mathrm{ml}$ blood loss in traditional method and $10 \mathrm{ml}$ in bipolar method, which was statistically significant. Similar findings was observed by Mofatteh MR. ${ }^{1}$

Postoperative pain assessment done with numerical pain rating scale in our study showed that there was no statistically significant difference at 2, 6, 12, 24 hours and 2 and 10 days postoperatively. This was similar to the result of Pang $\mathrm{YT}^{19}$, but different than Mofatteh $\mathrm{MR}^{1}$ and $\mathrm{Al}$-Shehri ${ }^{2}$ studies where the postoperative pain was high and low respectively in traditional dissection method when compared to bipolar method.

There was one case of primary hemorrhage in conventional dissection method which was treated with tranexamic acid. The occurrence was $3.33 \%$. The difference was statistically 
insignificant. Similar result was seen in Singh $\mathrm{OP}^{18}$ study where incidence of post operative hemorrhage was $5 \%$ in traditional method which was statistically insignificant when compared to bipolar method.

\section{LIMITATION}

The limitation of this study was small sample size.

\section{CONCLUSION}

In tonsillectomy, bipolar cauterization method has advantage over conventional dissection method in regards to reduced surgical time and intra operative blood loss, without any significant difference in post-operative pain intensity and postoperative hemorrhage.

\section{REFERENCES}

1. Mofatteh MR, Salehi F, Hosseini M, Hassanzadeh-Taheri $M$, Sharifzadeh G, Hassanzadeh-Taheri M. Comparison of postoperative morbidity between conventional cold dissection and bipolar electrocautery tonsillectomy: which technique is better? Braz J Otorhinolaryngol 2020;86(4):427-433.

2. Al-Shehri AMS, Alenzi HLS, Ali Mohammed YM, Musleh A, Bharti RK, Saeed Munshet AM. Cauterization tonsillectomy as compared to traditional tonsillectomy technique. J Family Med Prim Care 2020;9(8):39813985.

3. Collison PJ, Mettler B. Factors Associated with Posttonsillectomy Hemorrhage. Ear, Nose \& Throat Journal 2000;79(8):640-649.

4. Xu B, Jin HY, Wu K, Chen C, Li L, Zhang Y, Gu WZ, Chen C. Primary and secondary postoperative hemorrhage in pediatric tonsillectomy. World J Clin Cases 2021;9(7):1543-1553.

5. Sharma K, Kumar D. Ligation versus bipolar diathermy for hemostasis in tonsillectomy: a comparative study. Indian J Otolaryngol Head Neck Surg 2011;63(1):15-9

6. Burton MJ, Doree C. Harmonic scalpel versus other surgical procedures for tonsillectomy. Cochrane Database Syst Rev 2017(10):CD004616

7. Messner AH. Tonsillectomy. Operative Techniques in Otolaryngology-Head and Neck Surgery. $2005 ; 16(4): 224-28$

8. Obasikene G, Ramalingam R, Vadivu AS, Ramalingam KK. Newer Methods of Tonsillectomy as Compared to Conventional Dissection Method. J Pain Relief 2013; 3: 1-4.

9. Malik $\mathrm{S}$ et al. Compartive study between dissection and diathermy tonsillectomy. J. Baqai Med. Univ. 2006;9(1):7-11
10. Physiopedia contributors. Numeric Pain Rating Scale.In: Venus Pagare editor, Physiopedia;May2020:https://www. physiopedia. com/index.php?title=Numeric_Pain_Rating_ Scale\&oldid $=238203$.

11. Junior JFN, Herman DR, Americo RR, Stamm RG, Hirata CW. A brief history of tonsillectomy. Int Arch. Otorhinolaryngol. 2006;10(4):314-317.

12. Kumar A, Kumar S, Krishnan A. A Comparative Analysis of Outcomes of Conventional Cold Dissection Versus Laser Tonsillectomy in Pediatric Cases in a Tertiary Care Hospital in Haryana. Indian J Otolaryngol Head Neck Surg (2021). https://doi.org/10.1007/s12070020-02301-1

13. Karimi E, Safaee A, Bastaninejad S, Dabiran S, Masoumi E, Moravej Salehi F. A Comparison between Cold Dissection Tonsillectomy and Harmonic Scalpel Tonsillectomy. Iran J Otorhinolaryngol. 2017;29(95):313-317.

14. Baek MK, Kim YS, Choi SH et al. A Pilot Randomized Comparative Study of Two Diathermy Power Settings for Monopolar Microdissection and Bipolar Hemostasis during Tonsillectomy. Korean J Otorhinolaryngol-Head Neck Surg. 2016;59 (12): 836-42.

15. Beigh Z, Maqbool T, Deeba F. Bipolar electrocautery tonsillectomy vs cold dissection method tonsillectomy; our experience. Indian J. Appl. Res2017;7(12):278-79.

16. Mowatt G, Cook JA, Fraser C, McKerrow WS, Burr JM. Systematic review of the safety of electrosurgery for tonsillectomy. Clin Otolaryngol. 2006;31(2):95-102.

17. Aldrees T, Alzuwayed A, Majed A, Alzamil A, Almutairi M, Aloqaili Y. Evaluation of Secondary Post-Tonsillectomy Bleeding among Children in Saudi Arabia: Risk Factor Analysis. Ear Nose Throat J. 2020;145561320944662.

18. Singh, O. P., Khundrakpam, R., Sanasam, P. S., Marak, X. S., Arun, S., \& Keyho, V. (2020). Comparative Study between Cold Dissection and Bipolar Diathermy Dissection Methods of Tonsillectomy. IJHCR 2020; 3(9): 182-193.

19. Pang YT. Paediatric tonsillectomy: bipolar electrodissection and dissection/snare compared. J Laryngl Otol 1995;109(8):733-36. 